\title{
DNA demethylation is superior to histone acetylation for reactivating cancer-associated genes in ovarian cancer cells
}

\author{
CHUN-FENG MENG ${ }^{1}$, BO $\mathrm{SU}^{2}$ and $\mathrm{WEI} \mathrm{LI}^{3}$ \\ ${ }^{1}$ Department of Gynecology, First Affiliated Hospital, China Medical University, Shenyang; \\ ${ }^{2}$ Department of Orthopedics, Shenzhou Hospital, Shenyang Medical College, Shenyang; \\ ${ }^{3}$ Department of Gynecology, Shengjing Hospital, China Medical University, Shenyang, P.R. China
}

Received June 17, 2011; Accepted August 12, 2011

DOI: $10.3892 / \mathrm{mmr} .2011 .557$

\begin{abstract}
To investigate the contributions of histone $\mathrm{H} 3$ lysine 9 acetylation and DNA methylation to p16, hMLH1 and MGMT silencing in ovarian cancer cells, we treated three ovarian cancer cell lines with Trichostatin A (TSA) and 5-aza-2'-deoxycytidine and examined the status of mRNA expression, DNA methylation and histone $\mathrm{H} 3$ lysine 9 acetylation at the promoter of p16, hMLH1 and MGMT. The results showed that the hypermethylated silenced tumorrelated genes in the ovarian cancer cells were characterized by hypoacetylated histone H3 lysine 9. Treatment with TSA resulted in the increase of histone $\mathrm{H} 3$ lysine 9 acetylation at the hypermethylated promoter, but with little effects on gene expression. TSA did not contribute to DNA demethylation. 5-Aza-2'-deoxycytidine treatment caused DNA demethylation, increased histone H3 lysine 9 acetylation at the hypermethylated promoter and resulted in reactivation of p16, hMLH1 and MGMT. Combined treatments synergistically increased histone $\mathrm{H} 3$ lysine 9 acetylation accompanied by the re-expression of the hypermethylated genes. To conclude, in ovarian cancer cells, DNA methylation and histone deacetylation act synergistically for the silencing of cancer-associated genes. DNA demethylation is superior to histone acetylation for reactivating cancer-associated genes.
\end{abstract}

\section{Introduction}

Ovarian cancer is the most lethal malignancy of the female reproductive tract, and its survival rate remains much worse than the $61.5 \%$ overall cancer survival rate for women (1). Hence, novel approaches to understanding the etiology of ovarian cancer are warranted. Inactivation of genes crucial for

Correspondence to: Dr Chun-Feng Meng, Department of Gynecology, First Affiliated Hospital, China Medical University, 155 Nanjing North Street, Heping, Shenyang 110001, P.R. China E-mail: mcflovesb@gmail.com

Key words: ovarian cancer, p16, hMLH1, MGMT, epigenetic, DNA methylation, histone acetylation control of normal cell growth is a hallmark of cancer cells (2). Silencing of cancer-associated genes by allelic loss and somatic mutation has been reported in ovarian cancer, but these factors do not seem to be the main mechanism of silencing $(3,4)$.

Epigenetic silencing is the major alternative to accomplish cancer-associated gene inactivation (5). These epigenetic mechanisms mainly include crosstalk between DNA methylation and histone modification. Methylation of $\mathrm{CpG}$ islands has been associated with the silencing of a growing number of cancer-associated genes in numerous human cancers and has been proposed as the most common mechanism for gene regulation in cancer $(6,7)$. Methylation of a variety of cancer-associated genes has been reported in ovarian cancers (8-10).

Apart from DNA methylation, histone acetylation plays an important role in transcriptional regulation of a number of cancer-associated genes $(11,12)$. Different results have been reported in regards to the function of histone acetylation on gene expression. In Neurospora crassa and Brassica napus, the histone deacetylase inhibitor alone was found to reactivate methylated genes $(13,14)$. In addition, in human cancer, histone deacetylase inhibitors can reactivate several genes, including the estrogen receptor genes, FMR1, ARHI and MGMT (15-17). By contrast, several groups have shown that the DNA demethylating agent, but not the histone deacetylase inhibitor, reactivates the expression of hypermethylated tumorsuppressor genes in human colorectal cancer $(18,19)$.

The aim of this study was to investigate the effects of histone acetylation and DNA methylation on cancer-associated gene silencing and explore the relationship of histone $\mathrm{H} 3$ lysine 9 (H3-K9) acetylation and DNA methylation in ovarian cancer. Various genes are frequently hypermethylated and silenced in certain cancer types. They include the tumor-suppressor gene, p16, a mismatch repair gene, human mutL homolog 1 (hMLH1), and a DNA repair gene, O6-alkylguanine-DNA alkyltransferase (MGMT). The expression of these genes was examined following treatment with Trichostatin A (TSA), a histone deacetylase inhibitor and 5-aza-2'-deoxycytidine (5-aza-CdR), a DNA demethylating agent, in ovarian cancer cells. We found that histone deacetylation and DNA methylation act synergistically for the silencing of tumor-related genes. Furthermore, DNA demethylation is superior to histone acetylation for reactivating tumor-related genes. 
Table I. Primers and PCR conditions used in MSP.

\begin{tabular}{|c|c|c|c|c|}
\hline Gene & $\begin{array}{l}\text { Forward primer } \\
\text { sequence }\left(5^{\prime}-3^{\prime}\right)\end{array}$ & $\begin{array}{l}\text { Reverse primer } \\
\text { sequence }\left(5^{\prime}-3^{\prime}\right)\end{array}$ & $\begin{array}{l}\text { Product size } \\
\text { (bp) }\end{array}$ & $\begin{array}{l}\text { Annealing temp. }{ }^{\circ} \mathrm{C} \\
\text { (No. of PCR cycles) }\end{array}$ \\
\hline \multirow[t]{2}{*}{ MGMT } & M: GGTCGTTTGTACGTTCGC & GACCGATACAAACCGAACG & 116 & $60(3), 58(4), 56(5), 54(23)$ \\
\hline & U: GTAGGTTGTTTGTATGTTTGT & AACCAATACAAACCAAACA & 122 & \\
\hline \multirow[t]{2}{*}{ P16 } & M: TTATTAGAGGGTGGGGCGGATCGC & GACCCCGAACCGCGACCGTAA & 150 & $55(35)$ \\
\hline & U: TTATTAGAGGGTGGGGTGGATTGT & CAACCCCAAACCACAACCATAA & 151 & $55(35)$ \\
\hline \multirow[t]{2}{*}{ hMLH1 } & M: GATAGCGATTTTTAACGC & TCTATAАATTACTAААТСТСТTCG & 74 & $52(35)$ \\
\hline & U: AGAGTGGATAGTGATTTTTAATGT & АСТСТАТАААТТАСТАААТСТСТТСА & 115 & $52(35)$ \\
\hline
\end{tabular}

M, methylated sequence; $U$, unmethylated sequence.

Table II. Primers and PCR conditions used in RT-PCR.

\begin{tabular}{|c|c|c|c|c|c|}
\hline Gene & $\begin{array}{l}\text { Forward primer } \\
\text { sequence }\left(5^{\prime}-3^{\prime}\right)\end{array}$ & $\begin{array}{l}\text { Reverse primer } \\
\text { sequence }\left(5^{\prime}-3^{\prime}\right)\end{array}$ & $\begin{array}{l}\text { Product } \\
\text { size (bp) }\end{array}$ & $\begin{array}{l}\text { Annealing } \\
\text { temp. }{ }^{\circ} \mathrm{C}\end{array}$ & $\begin{array}{c}\text { PCR } \\
\text { cycle (no.) }\end{array}$ \\
\hline MGMT & CGAAATAAAGCTCCTGGGCA & GAACTCTTCGATAGCCTCGGG & 151 & 55 & 30 \\
\hline P16 & CAACGCACCGAATAGTTACGG & GCGCAGTTGGGCTCCG & 106 & 55 & 38 \\
\hline hMLH1 & AGTGGCTGGACAGAGGAAGA & GATCAGGCAGGTTAGCAAGC & 463 & 55 & 38 \\
\hline GAPDH & TCССАТСАССАТСТТССАG & ATGAGTCCTTCCACGATACC & 309 & 55 & 25 \\
\hline
\end{tabular}

\section{Materials and methods}

Cell culture conditions. The human ovarian cancer cell line CaOV3 (20), CoC1 and its DDP-resistant subline, CoC1/ DDP (21), was provided by the Oncology Institute of China Medical University. All of the cells were cultured in RPMI1640 medium (Gibco-BRL, USA) supplemented with $10 \%$ fetal bovine serum (Gibco) and incubated in an humidified incubator containing $10 \% \mathrm{CO}_{2}$ at $37^{\circ} \mathrm{C}$.

Treatment of cells with 5-aza-CdR and TSA. Cells were cultured for $24 \mathrm{~h}$ prior to the following treatments. 5-aza-CdR (1 $\mu \mathrm{M}$; Sigma, USA) was applied for $72 \mathrm{~h}$. Medium containing 5-aza-CdR was replaced every 24 h. TSA (300 nM; Sigma) was applied for only $24 \mathrm{~h}$. 5-aza-CdR $(1 \mu \mathrm{M})$ was applied for $48 \mathrm{~h}$ followed by TSA (300 $\mathrm{nM}$ ) for an additional $24 \mathrm{~h}$. Control cells were incubated without 5-aza-CdR or TSA, with replacement of fresh medium on the same schedule as that used for the drug-treated cells.

Methylation-specific polymerase chain reaction (MSP). Genomic DNA from the CaOV3, CoC1 and CoC1/DDP cells, treated as described above, was extracted with phenolchloroform:isoamyl alcohol and collected by ethanol precipitation. A 5- $\mu \mathrm{g}$ sample of genomic DNA was treated with sodium bisulfite (Sigma) as previously described (22). Briefly, DNA was denatured by incubation with $0.3 \mathrm{~mol} / 1$ $\mathrm{NaOH}$ at $37^{\circ} \mathrm{C}$ for $30 \mathrm{~min}$, followed by incubation with $10 \mathrm{mmol} / 1$ hydroquinone (Sigma) and $3 \mathrm{~mol} / 1$ sodium bisulfite (Sigma) at $55^{\circ} \mathrm{C}$ for $16-20 \mathrm{~h}$. Modified DNA was purified using a Wizard DNA Clean-Up System according to the manufacturer's protocol (Promega Corp., Madison, WI, USA).
The primers used for MSP are located in the promoter region of the genes. The $\mathrm{CpG}$ map of the promoter and the location of primers used in this study were based on a previous study (23). The primers used for MSP and additional PCR conditions are shown in Table I. Methyltransferase (Sss-I)-treated and untreated peripheral blood cell DNA from healthy adults were used as positive and negative controls, respectively. PCR products were separated by electrophoresis on $2 \%$ agarose gels. The gels were photographed using a ChemiImager 5500 automatic formatter (Alpha Innotech, San Leandro, USA). The experiment was repeated three times.

RNA extraction and reverse transcriptase-polymerase chain reaction ( $R T-P C R$ ). Total RNA from the $\mathrm{CaOV} 3, \mathrm{CoC} 1$ and CoC1/DDP cells, treated as described above, was extracted with TRIzol (Invitrogen, Carlsbad, USA) according to the manufacturer's protocol. cDNA was synthesized from $2 \mu \mathrm{g}$ total RNA using a Reverse Transcription System (Promega Corp.). The primers used for PCR and PCR conditions are shown in Table II. Glyceraldehyde-3-phosphate dehydrogenase (GAPDH) was used as the internal control. PCR products were resolved on $2 \%$ agarose gels and quantitated using the FluorChem 2.0 system. The expression level was determined by quantifying the intensities of the PCR product versus GAPDH. The experiment was repeated three times.

Real-time reverse transcriptase-polymerase chain reaction. Quantitative real-time PCR was carried out under optimized conditions using the following intron-spanning primers and Taqman probe, as shown in Table III. The PCR product was cloned into a pMD18-T vector and confirmed by sequencing. Purified recombinant plasmid DNA was quantified using a UV 
Table III. Primers and Taqman probes used in real time RT-PCR.

\begin{tabular}{llll}
\hline Gene & \multicolumn{1}{c}{ Forward primer sequence (5'-3') } & \multicolumn{2}{c}{ Reverse primer sequence (5'-3') } \\
\hline MGMT & CTC TTC ACC ATC CCG TTT TC & AGG GCT GCT AAT TGC TGG TA & GAA GGT TGT GAA ATT CGG AGA AGT GAT TTC \\
P16 & GGCTCCTCATTCCTCTTCCT & TCAGGTAGCGCTTCGATTCT & CAGAAGGGGTTTGTAATCACAGACCTCCT \\
hMLH1 & CAGAGGAAGATGGTCCCAAA & CAATCAGGTTCCCTTCCTCA & TGAGTTTCTGAAGAAGAAGGCTGAGATGC \\
\hline
\end{tabular}

Table IV. Primers and Taqman probes used in real time ChIP-PCR.

\begin{tabular}{llll}
\hline Gene & Forward primer sequence $\left(5^{\prime}-3^{\prime}\right)$ & Reverse primer sequence $\left(5^{\prime}-3^{\prime}\right)$ & Taqman probe \\
\hline MGMT & CCCCATCTCCAAATAAGGTCA & CCTAGACACTGCCAGAGCCTG & CTGGTGGACACAATTCAACTCCTAATAACG \\
P16 & GGCTCCTCATTCCTCTTCCT & TCAGGTAGCGCTTCGATTCT & CAGAAGGGGTTTGTAATCACAGACCTCCT \\
hMLH1 & CAGAGGAAGATGGTCCCAAA & CAATCAGGTTCCCTTCCTCA & TGAGTTTCTGAAGAAGAAGGCTGAGATGC \\
\hline
\end{tabular}

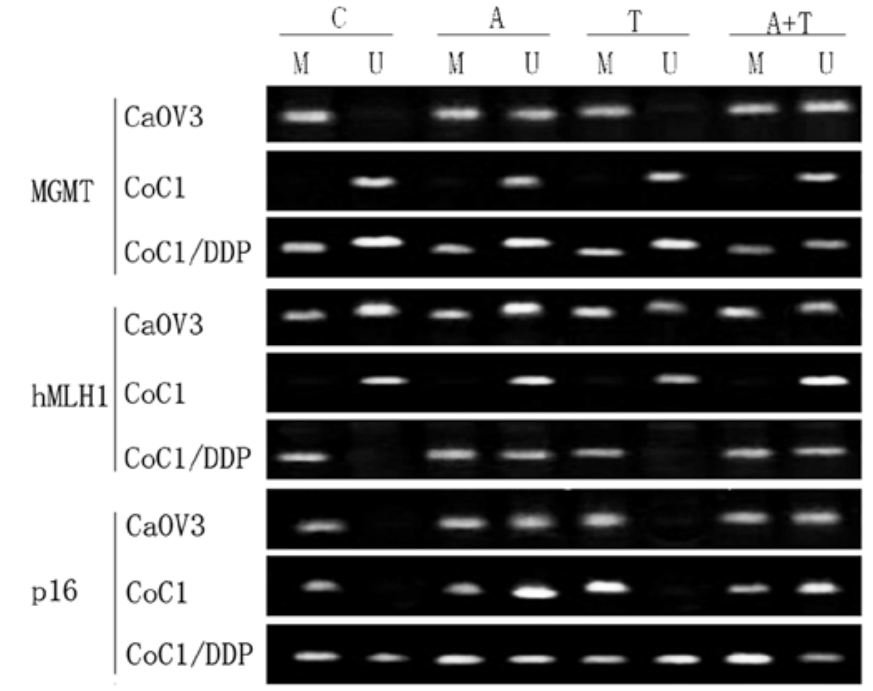

Figure 1. MSP analysis of DNA methylation at the MGMT promoter region before and after treatment of $\mathrm{CaOV} 3, \mathrm{CoC} 1$ and $\mathrm{CoC} 1 / \mathrm{DDP}$ cells with 5-azaCdR (A), TSA (T), or the combination (A+T). Lane M indicates the presence of methylated alleles. Lane $\mathrm{U}$ indicates the presence of unmethylated alleles. At least two independent experiments were performed with similar results. C, control.

spectrophotometer and then serially diluted to a final concentration range of $2 \times 10^{4}$ to $2 \times 10^{8}$ copies of genome equivalents/ $\mathrm{ml}$. Aliquots $(5 \mu \mathrm{l})$ of each dilution $\left(100-10^{6}\right.$ genome equivalents/reaction) were used for real-time PCR to create the standard curve used to quantify the experimental samples. Each sample was amplified in triplicate to obtain average copy numbers. Reactions without cDNA templates were used as a negative control.

Chromatin immunoprecipitation assay (ChIP). ChIP assays were performed as previously described with some modifications (24). Briefly, $\sim 1.75 \times 10^{7}$ cells, treated as described above, were fixed with $1 \%$ formaldehyde at $37^{\circ} \mathrm{C}$ for $20 \mathrm{~min}$, resuspended in lysis buffer ( $1 \%$ sodium dodecyl sulfate, $10 \mathrm{mmol} / \mathrm{l}$ EDTA, $50 \mathrm{mmol} / 1$ Tris-HCl, $\mathrm{pH}$ 8.1) and sonicated to generate 500-bp DNA fragments. The main soluble chromatin frac- tion was immunoprecipitated using an antibody against Lys-9 acetylated histone H3 (Upstate Biotechnology, Lake Placid, NY). The remaining soluble fraction was incubated with normal rabbit IgG (negative control) and used as a DNA input control. The cross-linking between DNA and proteins was reversed by heating the samples at $65^{\circ} \mathrm{C}$ for $5 \mathrm{~h}$, followed by proteinase $\mathrm{K}$ digestion. DNA was then extracted with phenol/ chloroform. ChIP experiments were repeated three times.

Real-time PCR analysis of immunoprecipitated DNA. Realtime PCR was performed using immunoprecipitated DNA, a negative control and a DNA input control. The primer probes for the $\mathrm{CpG}$ islands within the promoter region and Taqman probe are shown in Table IV. PCR was performed under optimized conditions. The segment of cDNA was cloned into the pMD18-T vectors and confirmed by sequencing. PCR reactions were carried out as described above.

Statistical analysis. The ratio results were expressed as mean \pm standard deviation (SD). Significance between controls and treated samples was calculated by the Student's t-test. Significance between the controls in the different cell lines was calculated using one-way ANOVA and q-tests. Statistical calculations were performed using SPSS version 10.0 (SPSS Inc., Chicago, IL, USA). p-values $<0.05$ were considered statistically significant.

\section{Results}

Differences in histone H3-K9 acetylation status under different promoter DNA methylation conditions. We investigated the status of DNA methylation and histone $\mathrm{H} 3-\mathrm{K} 9$ acetylation at the promoter region by using MSP and ChIP, respectively. The three cell lines had a characteristic DNA methylation status at the promoter region. As seen in Fig. 1, MGMT was hypermethylated (both alleles are methylated) in the $\mathrm{CaOV} 3$ cells, partially methylated (only one allele is methylated) in the CoC1/DDP cells, but was unmethylated (neither allele is methylated) in the $\mathrm{CoCl}$ cells. p16 was hypermethylated in the $\mathrm{CaOV} 3$ and $\mathrm{CoC} 1$ cells, but was unmethylated in the $\mathrm{CoCl} /$ DDP cells. hMLH1 was hypermethylated in CoC1/DDP cells, 

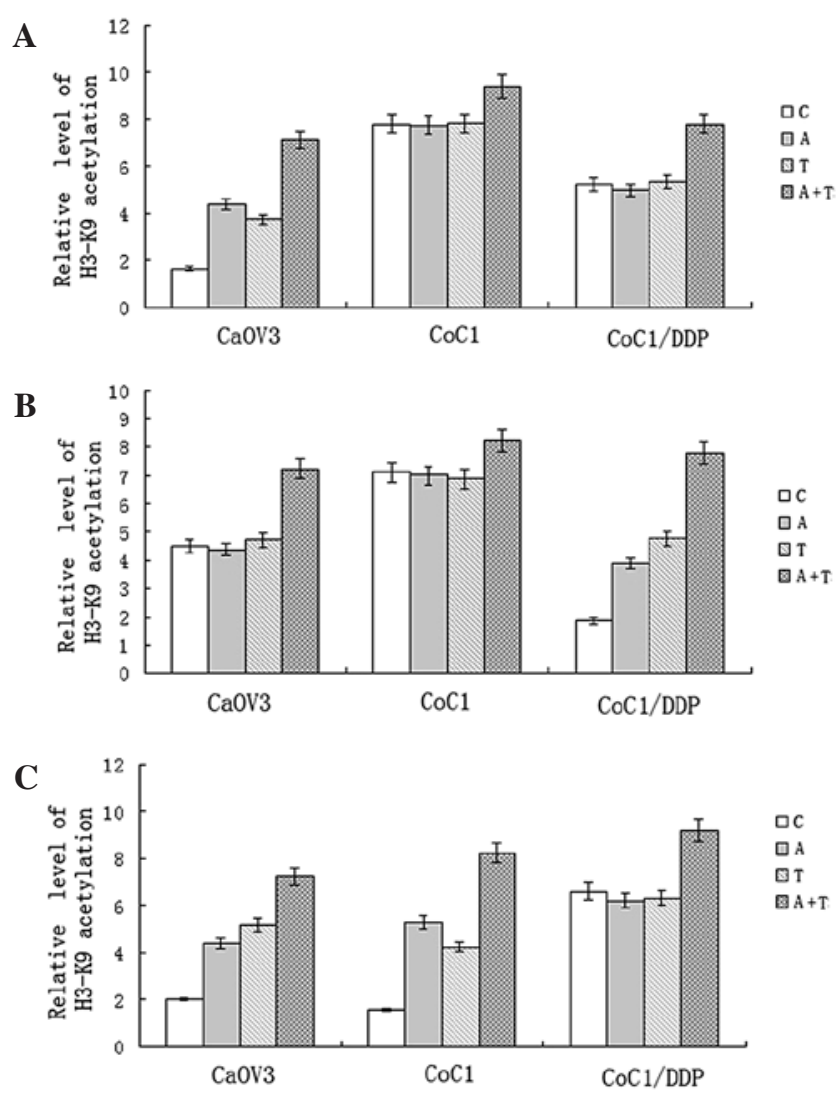

Figure 2. ChIP analysis of H3-K9 acetylation before and after treatment of the $\mathrm{CaOV} 3, \mathrm{CoC1}$ and $\mathrm{CoC1} / \mathrm{DDP}$ cells with 5-aza-CdR (A), TSA (T), or the combination $(\mathrm{A}+\mathrm{T})$. Real-time PCR experiments were repeated three times. The averaged ratios of precipitated DNA over input DNA shown on the $y$-axis represent the relative values of $\mathrm{H} 3-\mathrm{K} 9$ acetylation. Average $\mathrm{H} 3-\mathrm{K} 9$ acetylation levels are shown along with their standard error bars. (A) Summary of quantitative real-time PCR analysis of ChIP assays, using an antibody that recognizes acetyl-H3-K9 at the p16 promoter region. (B) Summary of quantitative real-time PCR analysis of ChIP assays, using an antibody that recognizes acetyl-H3-K9 at the hMLH1 promoter region. (C) Summary of quantitative real-time PCR analysis of ChIP assays, using an antibody that recognizes acetyl-H3-K9 at the MGMT promoter region. C, control

partially methylated in CaOV3 cells, but was unmethylated in the $\mathrm{CoC} 1$ cells.

Comparing Fig. 2 to Fig. 1, we found that acetylation of H3-K9 at the promoter region of the p16, hMLH1 and MGMT genes was inversely correlated with DNA methylation status. As shown in Fig. 2A, acetylation of H3-K9 at the promoter region of the MGMT gene was apparently higher in $\mathrm{CoC} 1$ (unmethylated) than in CoC1/DDP (partially methylated) cells and in CaOV3 cells (hypermethylated). Similar results were noted for the hMLH1 gene (Fig. 2B), which showed a low degree of $\mathrm{H} 3-\mathrm{K} 9$ acetylation in every part of the promoter region in the CoC1/DDP cells (hypermethylated). The highest degree of $\mathrm{H} 3-\mathrm{K} 9$ acetylation was detected in the $\mathrm{CoC} 1$ cells (unmethylated). An intermediate degree of $\mathrm{H} 3-\mathrm{K} 9$ acetylation was detected in the CaOV3 cells (partially methylated). In the CoC1/DDP cells, acetylation of $\mathrm{H} 3-\mathrm{K} 9$ at the promoter region of the p16 gene was apparently higher than that in the $\mathrm{CoC} 1$ and $\mathrm{CaOV} 3$ cells (Fig. 2C).

Gene silencing is associated with DNA methylation and H3-K9 acetylation at the promoter region. We examined
A

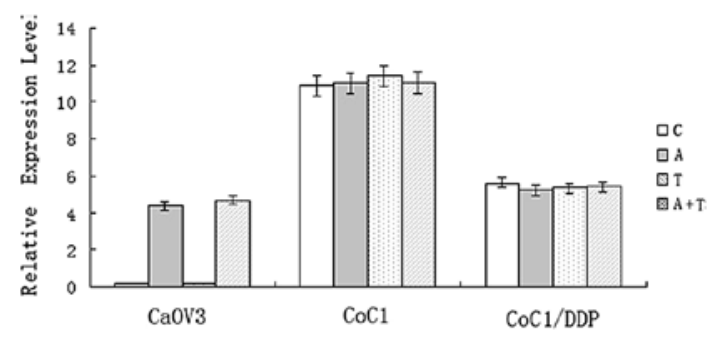

B

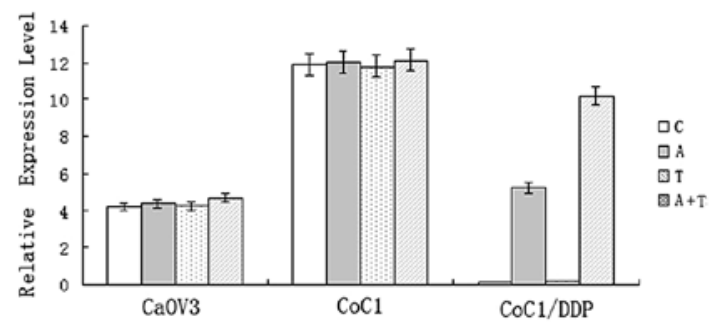

C

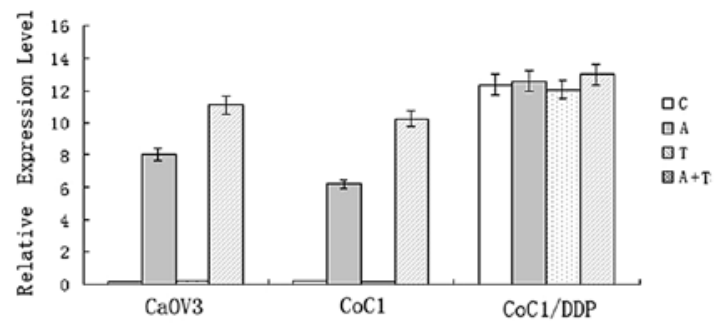

D

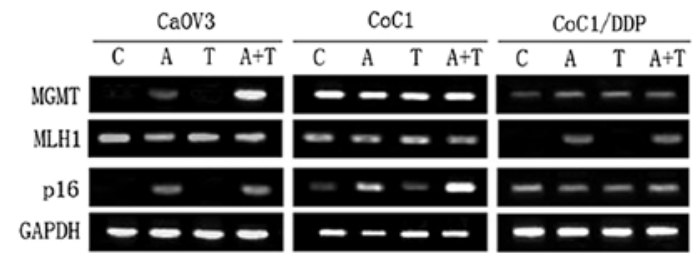

Figure 3. Real-time RT-PCR analysis of mRNA expression before and after treatment of $\mathrm{CaOV} 3, \mathrm{CoC} 1$ and $\mathrm{CoC1} / \mathrm{DDP}$ cells with 5-aza-CdR (A), TSA (T), or the combination (A+T). Real-time RT-PCR experiments were repeated three times, with expression levels normalized to each sample's respective GAPDH expression. Error bars were calculated as standard error of the mean from three independent experiment. (A) Summary of quantitative real-time PCR analysis of p16. (B) Summary of quantitative real-time PCR analysis of hMLH1. (C) Summary of quantitative real-time PCR analysis of MGMT. (D) Representative images of the PCR assay. C, untreated control.

mRNA expression of p16, hMLH1 and MGMT in three human ovarian cancer cell lines using RT-PCR. We found that DNA hypermethylation and H3-K9 hypoacetylation at the promoter region had a transcriptional silencing function in the p16, hMLH1 and MGMT genes. The promoter region in the gene-expressing cells was usually DNA hypomethylated and $\mathrm{H} 3-\mathrm{K} 9$ acetylated, whereas that of the gene-silenced cells was DNA hypermethylated and H3-K9 hypoacetylated. As shown in Fig. 3A and D, the MGMT gene was silenced in the CaOV3 cells, but expressed in the CoC1 and CoC1/DDP cells. hMLH1 was expressed in the $\mathrm{CaOV} 3$ and $\mathrm{CoC} 1$ cells, but silenced in the CoC1/DDP cells (Fig. 3B and D). p16 was silenced in the $\mathrm{CaOV} 3, \mathrm{CoC1}$, but expressed in the CoC1/DDP cells (Fig. 3C and D).

5-aza-CdR reactivates expression of the p16, MGMT and hMLH1 genes with DNA demethylation and an increase in H3-K9 acetylation at the DNA hypermethylated promoter. As 
shown in Figs. 2 and 3 treatment with 5-aza-CdR resulted in restoration of MGMT expression in hypermethylated $\mathrm{CaOV} 3$ cells, accompanied with DNA demethylation and an increase in $\mathrm{H} 3-\mathrm{K} 9$ acetylation. In $\mathrm{CoC} 1$ and $\mathrm{CoC} 1 / \mathrm{DDP}$ cells $(\mathrm{CpG}$ island was partially methylated or unmethylated), treatment with 5-aza-CdR minimally affected the expression of MGMT or the status of DNA methylation or the status of H3-K9 acetylation. 5-aza-CdR treatment resulted in demethylation, an increase in $\mathrm{H} 3-\mathrm{K} 9$ acetylation and re-expression of p16 in the $\mathrm{CaOV} 3$ and $\mathrm{CoC} 1$ cells, and similar results were noted for hMLH1 in the CoC1/DDP cells.

TSA increases H3-K9 acetylation at the DNA hypermethylated promoter without gene reactivation. We used ChIP assay to measure the effect of the treatment with TSA on the acetylation status of H3-K9 in ovarian cancer cell lines. Fig. 2 presents the results of ChIP assays in three ovarian cancer cell lines after treatment with TSA. Treatment with TSA alone had no effect on histone $\mathrm{H} 3-\mathrm{K} 9$ acetylation in cells with unmethylated DNA, but moderately increased histone H3-K9 acetylation in cells with hypermethylated DNA or partially methylated DNA. However, the combination of 5-aza-CdR and TSA increased histone H3-K9 acetylation effectively regardless of the DNA methylation status. Although TSA alone increased H3-K9 acetylation, it not only did not contribute to DNA demethylation, but also did not reactivate the expression of MGMT in the $\mathrm{CaOV} 3$ cells. The combined treatment resulted in demethylation of MGMT and restoration of MGMT expression in CaOV3 cells. In $\mathrm{CoC} 1$ and $\mathrm{CoC} 1 / \mathrm{DDP}$ cells $(\mathrm{CpG}$ island was partially methylated or unmethylated), treatment with TSA or a combination of the two agents minimally affected the status of H3-K9 acetylation, the expression of MGMT or the status of DNA methylation. The combined treatment resulted in an increase in H3-K9 acetylation, DNA demethylation and re-expression of p16 in CaOV3 and $\mathrm{COC} 1$ cells, and similar results were noted for hMLH1 in the CoC1/DDP cells. By contrast, TSA alone increased H3-K9 acetylation, but did not affect the DNA methylation status or the expression of p16 and hMLH1.

\section{Discussion}

In the present study, we showed that histone acetylation is correlated with transcriptional activity and is important for the establishment of initial silencing at the hypermethylated promoter. However, once silencing is established, inhibition of histone deacetylation does not result in activation of gene expression. DNA demethylation is superior to histone deacetylation for reactivating certain tumor-related genes at the hypermethylated promoter.

We found that the loss of expression of the p16, hMLH1 and MGMT genes was related to the epigenetic regulation of both DNA methylation and histone acetylation. Furthermore, histone $\mathrm{H} 3-\mathrm{K} 9$ acetylation in different regions of the promoters correlated well with the DNA methylation status of each gene. We found that, when the $\mathrm{CpG}$ island was hypermethylated, the lowest levels of histone H3-K9 acetylation were detected. When the $\mathrm{CpG}$ island was hypomethylated, the highest levels of acetylation were detected. When all $\mathrm{CpG}$ islands were partially methylated, the intermediate levels of acetylation were found.
From our data, we conclude that histone acetylation correlates with transcriptional activity and is important for the establishment of initial silencing at the hypermethylated promoter. The methylated $\mathrm{CpG}$-binding protein $\mathrm{MeCP} 2$ was found to be closely related to the inhibition complex which consists of the pontine proteins Sin3A and HDAC (25). MeCP2 bonds to chromatin by a DNA methylation-dependent pathway. The methylation of the promoter region and histone deacetylation are synergistic in the inhibition of gene transcription.

To deeply understand the contributions of histone acetylation and DNA methylation to gene silencing and to explore their relationship, we treated cells with 5-aza-CdR, TSA and performed ChIP assays. 5-aza-CdR, a demethylating agent, covalently bonds to DNA methyltransferases (DNMTs), reduces the biological activity of DNMTs, and thus lowers the methylation level regulating gene expression (26,27). After the action of 5-aza-CdR, the transcription inhibitor methyl-CpG binding domain (MBD) breaks away from the demethylated DNA or the transcription repression complex that originally binds to MBD, and then forms to its activated conformation of chromatic body (28). ChIP is a powerful tool for identifying proteins, including histone proteins and non-histone proteins, associated with specific regions of the genome by using specific antibodies that recognize a specific protein or a specific modification of a protein. The present ChIP assays demonstrated that the addition of 5-aza-CdR to ovarian cancer cells resulted in the demethylation of the p16, hMLH1 and MGMT genes accompanied with the re-expression of mRNA in the silenced cells.

Specific inhibition of HDACs by their inhibitors leads to the hyperacetylation of histones (29). Trichostatin A, a Streptomyces product originally discovered as a fungistatic antibiotic (30), was one of the first HDAC inhibitors identified. In the present study, inhibition of HDAC activities caused induction of histone deacetylation at the hypermethylated promoter. However, TSA hardly altered the mRNA expression level of p16, hMLH1 or MGMT. Our data support the observations that histone acetylation correlates with transcriptional activity and is important for the establishment of initial silencing at the hypermethylated promoter (31-33). However, once silencing is established, inhibition of histone deacetylation does not result in activation of gene expression (24). In the present study, at least we can conclude that DNA demethylation is superior to histone deacetylation in reactivating various tumor-related genes at the hypermethylated promoter, which is consistent with the previous observations (34).

Inhibition of DNA methylation by 5 -aza-CdR caused induction of histone deacetylation at the hypermethylated promoter and restored its mRNA expression in silenced ovarian cancer cells. The results strengthen the idea that there is some interdependence between reversal of histone acetylation and reactivation of a gene silenced by aberrant DNA hypermethylation. Furthermore, that a combination of TSA and 5-aza-CdR was able to activate the expression of p16, hMLH1 and MGMT with an increase in the histone acetylation level, and showed a synergetic effect, suggests that the TSA-mediated positive regulation demands the initial promoter demethylation by 5-aza-CdR.

In our previous study, we demonstrated that TSA alone was able to reactivate the expression of the MGMT gene, without 
altering its DNA methylation status (35). At the same time, we noted that the reactivation of MGMT was associated with the initial status of DNA methylation at the promoter region. We found that when the promoter region was hypermethylated before drug treatment, TSA alone was able to reactivate the silenced gene. When the promoter region was partially methylated or unmethylated, TSA alone was not able to reactivate the silenced gene. The results that MGMT, as well as p16 and hMLH1, can be regulated by a DNA methylation-dependent pathway suggests that DNA methylation and histone deacetylation may be tightly coupled in transcriptional regulation.

In conclusion, in ovarian cancer cells, DNA methylation and histone deacetylation act synergistically for the silencing of cancer-associated genes. DNA methylation played the leading role in the gene transcriptional regulation. The combination of 5-aza-CdR and TSA resulted in markedly increased histone $\mathrm{H} 3-\mathrm{K} 9$ acetylation in all cells and was most effective at restoration of gene expression. Our findings may provide a foundation to explore the molecular mechanisms of ovarian cancer and to utilize these epigenetic modification targets for pharmacologic intervention in ovarian cancer patients.

\section{Acknowledgements}

This project was supported by a grant from the Scientific Research Foundation to Dr Liaoning of China (no. 20091112).

\section{References}

1. Barnholtz-Sloan JS, Schwartz AG, Qureshi F, Jacques S, Malone J and Munkarah AR: Ovarian cancer: changes in patterns at diagnosis and relative survival over the last three decades. Am J Obstet Gynecol 189: 1120-1127, 2003.

2. Hanahan D and Weinberg RA: The hallmarks of cancer. Cell 100: 57-70, 2000.

3. Cliby W, Ritland S, Hartmann L, et al: Human epithelial ovarian cancer allelotype. Cancer Res 53: 2393-2398, 1993.

4. Sato T, Saito H, Morita R, et al: Allelotype of human ovarian cancer. Cancer Res 51: 5118-5122, 1991.

5. Esteller M and Herman JG: Cancer as an epigenetic disease: DNA methylation and chromatin alterations in human tumors. J Pathol 196: 1-7, 2002.

6. Herman JG and Baylin SB: Gene silencing in cancer in association with promoter hypermethylation. N Engl J Med 349: 2042-2054, 2003.

7. Baylin SB and Herman JG: DNA hypermethylation in tumorigenesis: epigenetics joins genetics. Trends Genet 16: 168-174, 2000.

8. Wiley A, Katsaros D, Chen H, et al: Aberrant promoter methylation of multiple genes in malignant ovarian tumors and in ovarian tumors with low malignant potential. Cancer 107: 299-308, 2006.

9. Yap OW, Bhat G, Liu L, et al: Epigenetic modifications of the estrogen receptor $\beta$ gene in epithelial ovarian cancer cells. Anticancer Res 29: 139-144, 2009.

10. Makarla PB, Saboorian MH, Ashfaq R, et al: Promoter hypermethylation profile of ovarian epithelial neoplasms. Clin Cancer Res 11: 53-65, 2005.

11. Gui CY, Ngo L, Xu WS, et al: Histone deacetylase (HDAC) inhibitor activation of p21WAF1 involves changes in promoterassociated proteins, including HDAC1. Proc Natl Acad Sci USA 101: 1241-1246, 2004.

12. Puri PL, Iezzi S, Stiegler P, et al: Class I histone deacetylases sequentially interact with MyoD and pRb during skeletal myogenesis. Mol Cell 8: 885-897, 2001.
13. Chen ZJ and Pikaard CS: Epigenetic silencing of RNA polymerase I transcription: a role for DNA methylation and histone modification in nucleolar dominance. Genes Dev 11: 2124-2136, 1997.

14. Selker EU: Trichostatin A causes selective loss of DNA methylation in Neurospora. Proc Natl Acad Sci USA 95: 9430-9435, 1998.

15. Yang X, Ferguson AT, Nass SJ, et al: Transcriptional activation of estrogen receptor alpha in human breast cancer cells by histone deacetylase inhibition. Cancer Res 60: 6890-6894, 2000.

16. Chiurazzi P, Pomponi MG, Pietrobono R, et al: Synergistic effect of histone hyperacetylation and DNA demethylation in the reactivation of the FMR1 gene. Hum Mol Genet 8: 2317-2323, 1999.

17. Chen Y, Sharma RP, Costa RH, et al: On the epigenetic regulation of the human reelin promoter. Nucl Acids Res 30: 2930-2939, 2002.

18. Cameron EE, Bachman KE, Myohanen S, et al: Synergy of demethylation and histone deacetylase inhibition in the re-expression of genes silenced in cancer. Nat Genet 21: 103-107, 1999.

19. Suzuki H, Gabrielson E, Chen W, et al: A genomic screen for genes up-regulated by demethylation and histone deacetylase inhibition in human colorectal cancer. Nat Genet 31: 141-149, 2002.

20. Goncharenko-Khaider N, Lane D, Matte I, Rancourt C and Piché A: The inhibition of Bid expression by Akt leads to resistance to TRAIL-induced apoptosis in ovarian cancer cells. Oncogene 29: 5523-5536, 2010.

21. Yang X, Xing H, Gao Q, Chen G, Lu Y, Wang S and Ma D: Regulation of HtrA2/Omi by X-linked inhibitor of apoptosis protein in chemoresistance in human ovarian cancer cells. Gynecol Oncol 97: 413-421, 2005.

22. Herman JG, Graff JR, Myohanen S, et al: Methylation-specific PCR: a novel PCR assay for methylation status of $\mathrm{CpG}$ islands. Proc Natl Acad Sci USA 93: 9821-9826, 1996.

23. Kondo Y, Shen L and Issa JP: Critical role of histone methylation in tumor-suppressor gene silencing in colorectal cancer. Mol Cell Biol 23: 206-215, 2003.

24. Meng CF, Zhu XJ, Peng G and Dai DQ: Promoter histone H3 lysine 9 di-methylation is associated with DNA methylation and aberrant expression of p16 in gastric cancer cells. Oncol Rep 22: 1221-1227, 2009.

25. Nan X, Ng HH, Johnson CA, et al: Transcriptional repression by the methyl-CpG-binding protein $\mathrm{MeCP} 2$ involves a histone deacetylase complex. Nature 393: 386-389, 1998.

26. Christman JK: 5-Azacytidine and 5-aza-2'-deoxycytidine as inhibitors of DNA methylation: mechanistic studies and their implications for cancer therapy. Oncogene 21: 5483-5495, 2002.

27. Lyko F and Brown R: DNA methyltransferase inhibitors and the development of epigenetic cancer therapies. J Natl Cancer Inst 97: 1498-1506, 2005.

28. Shi H, Wei SH, Leu YW, et al: Triple analysis of the cancer epigenome: an integrated microarray system for assessing gene expression, DNA methylation, and histone acetylation. Cancer Res 63: 2164-2171, 2003.

29. Marks PA, Richon VM, Miller T, et al: Histone deacetylase inhibitors. Adv Cancer Res 91: 137-168, 2004.

30. Tsuji N, Kobayashi M, Nagashima K, et al: A new antifungal antibiotic, trichostatin. J Antibiot 29: 1-6, 1976.

31. Allfrey V, Faulkner RM and Mirsky AE: Acetylation and methylation of histones and their possible role in the regulation of RNA synthesis. Proc Natl Acad Sci USA 51: 786-794, 1964.

32. Turner BM: Decoding the nucleosome. Cell 75: 5-8, 1993.

33. Bird AP and Wolffe AP: Methylation-induced repression-belts, braces, and chromatin. Cell 99: 451-454, 1999.

34. Fahrner JA, Eguchi S, Herman JG, et al: Dependence of histone modifications and gene expression on DNA hypermethylation in cancer. Cancer Res 62: 7213-7218, 2002.

35. Meng CF, Zhu XJ, Peng G and Dai DQ: Role of histone modifications and DNA methylation in the regulation of O6-methylguanine-DNA methyltransferase gene expression in human stomach cancer cells. Cancer Invest 28: 331-339, 2010. 